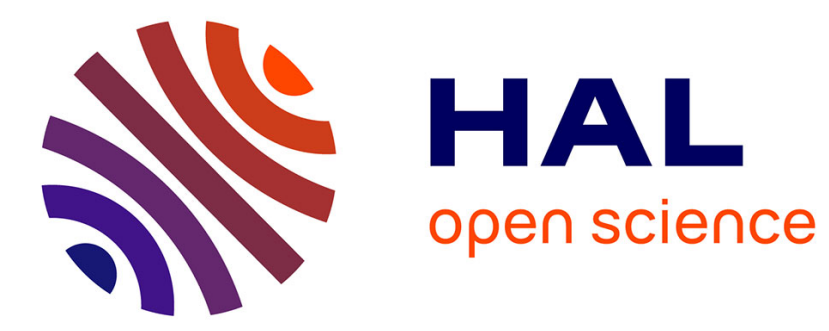

\title{
CAPTURE CROSS-SECTIONS OF DEEP LEVELS IN SUPERLATTICES
}

\author{
D. Stievenard, Dominique Vuillaume, S. Feng, J. Bourgoin
}

\section{To cite this version:}

D. Stievenard, Dominique Vuillaume, S. Feng, J. Bourgoin. CAPTURE CROSS-SECTIONS OF DEEP LEVELS IN SUPERLATTICES. Journal de Physique Colloques, 1987, 48 (C5), pp.C5-247C5-250. 10.1051/jphyscol:1987552 . jpa-00226756

\section{HAL Id: jpa-00226756 https://hal.science/jpa-00226756}

Submitted on 1 Jan 1987

HAL is a multi-disciplinary open access archive for the deposit and dissemination of scientific research documents, whether they are published or not. The documents may come from teaching and research institutions in France or abroad, or from public or private research centers.
L'archive ouverte pluridisciplinaire HAL, est destinée au dépôt et à la diffusion de documents scientifiques de niveau recherche, publiés ou non, émanant des établissements d'enseignement et de recherche français ou étrangers, des laboratoires publics ou privés. 
CAPTURE CROSS-SECTIONS OF DEEP LEVELS IN SUPERLATTICES

\author{
D. STIEVENARD, D. VUILlaume, S.L. FENG* and J.C. BOURGOIN*
}

Laboratoire de Physique des Solides (UA 253), Institut Supérieur d'Electronique du Nord, 41, Bd Vauban, F-59046 Lille Cedex, France

*Groupe de Rhysique des Solides de I'Ecole Normale supérieure. Université Paris VII, T-23, 2, Place Jussieu, F-75251 Paris Cedex 05, France

RÉSUMÉ

La spectroscopie de transitoires de capacité peut être utilisée pour caractériser les super-réseaux et les défauts qu'ils contiennent. Ici nous décrivons la mesure de section de capture d'électrons sur des niveaux profonds introduits par irradiation d'électrons. La variation du taux de capture avec la température indique que cette capture se produit par émission multiphonon, dont les caractéristiques peuvent être prédites en prenant en compte la structure de bande du superréseau.

ABSTRACT

Transient capacitance spectroscopy can be used to characterize superlattices and the defects they contain. Here, we describe the measurement of electron capture cross-sections of deep levels introduced by electron irradiation. The variation of the capture rate versus temperature indicates that this capture occurs through a multiphonon emission process whose characteristics can be predicted in taking into account the superlattice band structure.

\title{
I - INTRODUCTION
}

Band edge discontinuity and position of the superlattice miniband are fundamental parameters required for device modeling. One original way to study these parameters is the use of deep levels as local probes [1]. Such defects are highly localized (the wave function extension is typically limited to the first neighbor shell) so that they are not sensitive to the surrounding potential wells, even for narrow thickness of the well $(\sim 20 \AA)$. Then, the corresponding energy levels (relatively to the original bulk materials, i.e. GaAs or GaAlAs in the case considered here) remain the same in the superlattice structure as in the bulk materials. Therefore, when these energy levels are known in the two bulk materials, a study of the electronic transitions from the defect level to the bands provides direct information on the superlattice band structure. Such type of study has been performed on periodic $(20-20 \AA)$, GaAs-GaAlAs $\left(30 \%\right.$ Al) n-type Si $\left(3 \times 10^{16}\right.$ $\left.\mathrm{cm}^{-3}\right), 1.7 \mu \mathrm{m}$ thick structures using as probes defects created by electron irradiation [2]. These defects are detected using Deep Level Transient Spectroscopy (DLTS). In the superlattice, four main defects, labelled SE1, SE2, SE3 and SE4 are detected which are located respectively at $0.140,0.185,0.34$ and $0.55 \mathrm{eV}$ below the bottom of the first conduction miniband. Using the fact that the energy level positions, $S E$, for a defect in a superlattice are related to those of GaAs $\left(E_{i}\right)$ and GaAlAs ( $E_{k}$ ) through

$$
\mathrm{SE}_{\mathbf{i}}=\mathrm{E}_{\mathbf{i}}+\delta \text { and } \mathrm{SE}_{\mathrm{k}}=\mathrm{E}_{\mathrm{k}}-\Delta+\delta
$$

where $\delta$ and $\Delta$ are respectively the position of the bottom of the superlattice miniband above the conduction band edge of GaAs and $\Delta$ the conduction band discontinuity. From the results obtained we deduced $\delta=0.140 \mathrm{eV}$ and $\Delta=0.270 \mathrm{eV}$ (see Table I), i.e. a $64-36 \%$ offset in good agreement with recently published data $[3,4]$. In fact, relation (1) is we11 verified for the levels SE1 and SE2, but poorIy for SE3 and SE4. This discrepancy may be explained by the existence of an activation energy $\left(E_{B}\right)$ associated with the capture cross-section. 


\begin{tabular}{|c|c|c|c|c|c|c|}
\hline & \multicolumn{3}{|c|}{ Bulk Material } & \multicolumn{3}{|c|}{ Superlattice } \\
\hline & Level & $\mathrm{E}_{\mathrm{T}}(\mathrm{eV})$ & $E_{B}(e v)$ & Level & $\mathrm{E}_{\mathrm{T}}+\mathrm{E}_{\mathrm{B}}(\mathrm{eV})$ & Origin \\
\hline \multirow[t]{3}{*}{ GaAs } & E1 & 0.045 & - & $\mathrm{SEl}$ & 0.140 & $E^{\prime} 2$ \\
\hline & E2 & 0.140 & $\sim 0$ & $\mathrm{SE} 2$ & 0.185 & E1 \\
\hline & E3 & 0.300 & 0.1 & SE3 & 0.340 & E2 \\
\hline \multirow[t]{3}{*}{ GaAlAs } & $E^{\prime} 1$ & 0.180 & - & SE4 & 0.550 & $E 3+E^{\prime} 3$ \\
\hline & $E^{\prime} 2$ & 0.270 & - & & & \\
\hline & $E^{\prime} 3$ & 0.690 & 0.14 & & & \\
\hline
\end{tabular}

Table $I$ - Characteristics of the defects (ionization energy $E_{T}$ and barrier $E_{B}$ ) introduced by electron irradiation in GaAs, GaAlAs and in a $20-20 A$ GaAlAs-GaAs superlattice.

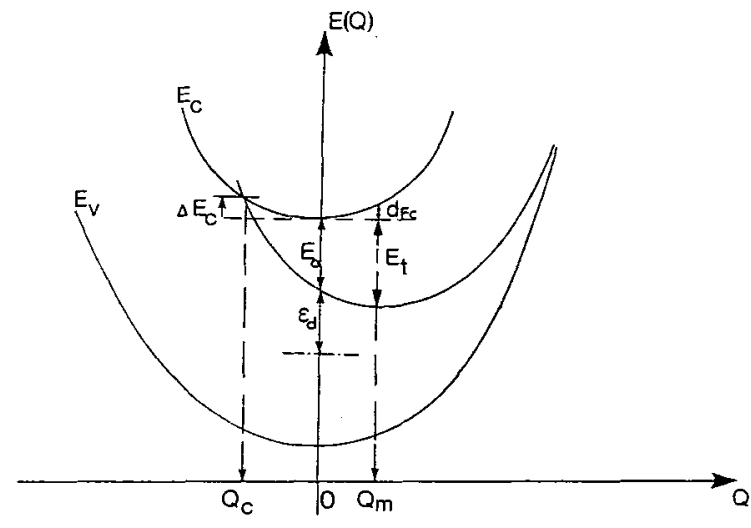

Figure 1 : Configuration coordinate diagram of a deep level; $\Delta E_{c}$ represents the bartier an electron in the conduction band has to overcome in order to get trapped on the defect.

DLTS provides an apparent ionization energy which is the sum, $\mathrm{E}_{\mathrm{T}}+\mathrm{E}_{\mathrm{B}}$, where $E_{T}$ is the ionization energy for the emission of an electron from the defect to the conduction band (i.e. the location of the energy level in the gap). As to $E_{B}$, it is a barrier (see figure 1) which reflects the fact that the capture cross-section is thermally activated when it occurs via a multiphonon (MPE) process $[5,7]$. Consequently, in order to obtain a good fit of expression (1) with the experimental results, it is necessary to perform independent measurements of the defect capture cross-section a versus temperature in order to determine $\mathbf{E}_{B}$.

The aim of this communication is to describe measurements of $\sigma$, performed for some of the observed defects, in order to obtain $E_{B}$ and to examine the change of the capture rate which occurs when a defect is placed in the superlatice. We shall see that this change can be accounted for by the new band structure, as is expected when the capture occurs through the MPE process. 


\section{II - EXPERIMENTAL RESULTS}

The study of the capture kinetics is performed using filling pulses of width $t_{p}$ in the range $50 \mathrm{~ns}-20 \mathrm{~ms}$. The kinetics, given by the amplitude $A$ of the DLTS peak versus $t_{p}$ allows to determine $a[8]$ for a given temperature. The measurements performed for vartous emission rates provide $\sigma(T)$ which is fitted by

$$
\sigma=\sigma_{\infty} \exp -E_{B} / k T
$$

in order to obtain $\mathbb{E}_{\mathfrak{B}}$.

The results are the following:

1. SE1 and $S E 2$ are already filled for $t_{p}=50 \mathrm{~ns}$.

2. It has not been possible to make a precise analysis in the case of SE3 because this level just appears a shoulder of the main peak SE4 [1].

3. As to SE4, its capture cross-section varies with temperature, as shown in figure 2, and we determine, using the slope of $A\left(t_{p}\right)$ near the origin or a fitting program on ail the experimental points, $E_{B}=0.145 \pm 0.055 \mathrm{eV}$. (The large error is related to the fact that we used two different techniques to measure $E_{B}$ ). If we compare the value found for $E_{B}$ with the one we can deduce from the direct measurement of $E_{T}+E_{B}$ by DLTS and from the value of $E_{T}$ which is predicted by equation (1), (see Table $I$ ), the agreement is good.

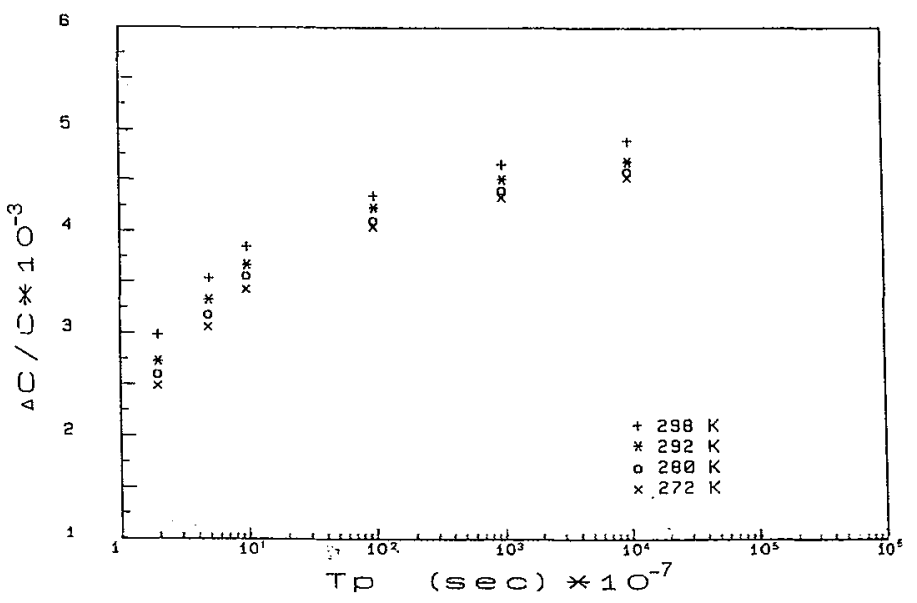

Figure 2 : Amplitude of the capacitance transient versus filling time for the defect $S E 4$ at various temperatures.

\section{IV - DISCUSSION}

Here we shall discuss the result obtained for SE4 and examine if it can be accounted for in terms of a multiphonon capture by introducing the superlattice band structure. In the MPE process $\mathrm{E}_{\mathrm{B}}$ is the barrier $\Delta \mathrm{E}_{\mathrm{C}}$, noted on the configuration coordinate diagram of figure 1 , that an electron in the conduction band must overcome to get on the localized state $E_{T}$. The abscissa $Q_{c}$ at which the two curves $\mathrm{E}_{\mathrm{C}}(\mathrm{Q})$ and $\mathrm{E}_{\mathrm{T}}(\mathrm{Q})$ cross each other, corresponding to the total energies of the defect with the electron in the band and with the electron localized on $E_{T}$ respectively, provides the barrier

$$
\mathrm{E}_{\mathrm{B}}=\frac{1}{2} \mathrm{kQ}_{\mathrm{C}}^{2}
$$

Taking the origin of the energies at the middle of the gap $\mathrm{Eg}$, we can write : 


$$
\begin{aligned}
& E_{c}(Q)=E g / 2+\frac{1}{2} \mathrm{kQ}^{2} \\
& E_{T}(Q)=\varepsilon_{d}+\frac{1}{2} \mathrm{kQ}^{2}-\mathrm{IQ} \\
& \varepsilon_{\mathrm{d}}=\mathrm{Eg} / 2-\mathrm{E}_{\mathrm{T}}+\mathrm{d}_{\mathrm{F}}
\end{aligned}
$$

where $k=\mathrm{Mas}^{2}$ ( $M$ is the reduced mass and whe phonon pulsation) and $d_{F_{C}}$ the Franck Codon Shift. Thus, in bulk material,

$$
\mathrm{E}_{\mathrm{B}}=\frac{1}{2} \mathrm{k} / \mathrm{I}^{2}\left(\mathrm{~d}_{\mathrm{F}}-\mathrm{E}_{\mathrm{T}}\right)^{2}
$$

In the superlattice, equation ( 3 ) is remplaced by :

and

$$
E_{c}(Q)=E g / 2+\frac{1}{2} \mathrm{k} Q^{2}+\delta \quad \text { for a GaAs layer }
$$

$$
E_{C}(Q)=E g / 2+\frac{1}{2} k Q^{2}-\Delta+\delta \quad \text { for a GaAlAs layer }
$$

which lead to :

and

$$
\mathrm{E}_{\mathrm{B}}^{\prime}=\frac{1}{2} \dot{\mathrm{k}} / \mathrm{I}^{2}\left(-\mathrm{E}_{\mathrm{T}}+\mathrm{d}_{\mathrm{F}_{\mathrm{c}}}-\delta\right)^{2} \quad \text { in GaAs }
$$

$$
E_{B}^{* \prime}=\frac{1}{2} k / I^{2}\left(-E_{T}+d_{F_{C}}-\delta+\Delta\right)^{2} \text { in GaAlAs }
$$

The constant $k$ and $I$ remain the same as in the bulk material since the defect being localized, keeps the characteristical properties it has in the bulk.

Consider now the defect SE4, which we know corresponds to a level (E3) in GaAs whose characteristics are $: \mathrm{E}_{\mathrm{T}}=0.30 \mathrm{eV}(2), \mathrm{E}_{\mathrm{B}}=0.10 \mathrm{eV}(2)$ and $\mathrm{d}_{\mathrm{F}}=0.075$ to $0.2 \mathrm{eV}(9)$. Equation (10) then provides $E_{B}^{\prime}=0.25$ to $0.55 \mathrm{eV}$. The agreement with the experimental result is poor, probably due to the large uncertainty on $d_{F_{C}}$ and to the fact that SE4 contains a second component E' 3 (see Table I). However, for the defect $\mathrm{SE} 3$ which corresponds to the defect $\mathrm{E} 2$ in $\mathrm{GaAs}\left(\mathrm{E}_{\mathrm{T}}=0.14 \mathrm{eV}, \mathrm{E}_{\mathrm{B}}=0\right.$ ) we get $E_{B}^{\prime}=0.055 \mathrm{eV}$ in good agreement with the value $(0.06 \mathrm{eV})$ deduced by equation

In conclusion, these preliminary measurements of capture cross-sections for defects in GaAs-GaAlAs superlattices indicate that the capture occurs through a multiphonon process as in the original bulk material. A simple model of configuration coordinate diagram seems to be sufficient to allow a reasonable prediction of these quantities.

\section{REFERENCES}

1. D. Stievenard, D. Vuillaume, J.C. Bourgain, B. Deveaud and A. Regreny Europhysics Lett. $2(4), 331$ (1986).

2. D. Pons and J.C. Bourgoin

J. Phys. C: Solid State Phys. 18, 3839 (1985).

3. H. Kroemer Surface Science 174, 229 (1986).

4. W.I. Wang, E.E. Mendez and F. Stern Appl. Phys. Lett. 45, 639 (1984).

5. K. Huang and A. Rhys Proc. Roy. Soc. (London), 204 A, 406 (1950).

6. D.V. Lang and C.H. Henry Phys. Rev. Lett. 35, 1525 (1975).

7. J.C. Bourgoin and M. Lannoo Point Defects in Semiconductors (Springer, Berlin, 1983), chap. 6.

8. D. Stievenard, J.C. Bourgoin and M. Lannoo

J. Appl. Phys. 55, 1477 (1984).

9. S. Makram-Ebeid and M. Lannoo Phys. Rev. B 25, 6406 (1982).

10. S. Loualiche, A. Nouilhat, G. Guillot and M. Lannoo Phys. Rev. B 30, 10, 5822 (1984).

\section{ACKNOWLEDGEMENT}

This work has been supported by a CNET contract ( ${ }^{\circ} 86.6$ B007909245). 